\title{
VOZES QUE ECOAM DO MORRO MILENAR: UM ESTUDO SOBRE OS DISCURSOS DIFUNDIDOS NO ANUÁRIO COLUNAS DO INSTITUTO PORTO ALEGRE (1937-1954)
}

\author{
Voices that echo the Morro Milenar: a study of the \\ speeches broadcast on year book Colunas of Porto \\ Alegre Institute (1937-1954)
}

Valeska Alessandra de Lima*

Dóris Bittencourt Almeida**

\begin{abstract}
RESUMO
Este trabalho é produto da pesquisa Escritos de alunos: memórias de culturas juvenis (19401960), que toma como objeto de investigação os periódicos produzidos por alunos de diferentes instituições escolares de Porto Alegre/RS. O estudo vincula-se aos pressupostos teóricos da História Cultural e inscreve-se no campo da História da Educação em suas interfaces com a Imprensa Escolar e a História das Instituições Educacionais.O foco da análise foi perceber as marcas deixadas pelos jovens no periódico Colunas, anuário produzido pelo Instituto Porto Alegre/IPA, procurando distinguir indícios de saberes e práticas escolares que evidenciam as identidades daqueles sujeitos. A estratégia metodológica utilizada foi o exame da materialidade e dos discursos difundidos em textos e imagens ao longo de doze edições. Percebe-se que, embora o IPA estimulasse um certo protagonismo estudantil na edição do Colunas, mimetizavam o formato estético e discursivo dos
\end{abstract}

* Universidade Federal do Rio Grande do Sul - Mestranda - PPGEDU/UFRGS - Fone: 51-92757572 - Endereço: Faculdade de Educação - Prédio 12201 - Av. Paulo Gama, s/n CEP 90046-900 - Fax: 33083985 - Email: lima_valeska@yahoo.com.br

** Universidade Federal do Rio Grande do Sul - Doutora em Educação - PPGEDU/ UFRGS - Endereço: Faculdade de Educação - Prédio 12201 - Av. Paulo Gama, s/n CEP 90046-900 - Fax: 33083985 - Email: almeida.doris@gmail.com 
yearbook'snorteamericanos. O caráter institucional do periódico não impediu que as vozes dos alunos ecoassem nas páginas do anuário. Em meio à profusão de fotografias e notícias do colégio, eles se fazem notar, especialmente nos textos biográficos dos colegas, nas montagens fotográficas e nas charges. Essas são marcas dos discentes, talvez pouco perceptíveis em um primeiro olhar, mas que se revelam na observação atenta desta fonte importante para a História da Educação.

Palavras-chave: Periódicos Estudantis. Memórias Juvenis. Práticas de Leitura e Escrita

\begin{abstract}
ThisworkistheproductofresearchStudentsWritings: Memories ofyouthcultures (19401960), whichfocusesonresearchjournalsproducedbystudentsofdifferenteducationalinstitutionsof Porto Alegre / RS. The studyislinkedtothetheoreticalassumptionsof Cultural HistoryandfallswithinthefieldofHistoryofEducationat its interfaces withtheSchool Press andtheHistoryofEducationalInstitutions. The focusoftheanalysiswastoseethemarksleftbyyouth in regular Colunas, yearbookproducedbythe Porto Alegre Institute / IPA, seekingtodistinguishevidenceofknowledgeandschoolpracticesthatrevealtheidentitiesofthosesubjects. The methodological approach wasthetestofmaterialityandthe speeches broadcast ontextsandimages over twelveeditions. It isnoticedthat, althoughthe IPA stimulate a certain role in thestudenteditionof Colunas, mimickedtheaes theticanddiscursiveformatofAmerican'syearbook. The institutionalcharacterofthejournaldidnot stop thestudents' voicesechoed in thepagesoftheyearbook. Amidsttheprofusionofphotographsandstoriesofthecollege, they are remarkable, especially in biographicaltextsfromcolleagues, in thecartoonsandphotomontages. These are marksofstudents, perhapsbarelynoticeableatfirstglance, butrevealed in thecarefulobservationofthisimportant for theHistoryofEducationsource.
\end{abstract}

Keywords: StudentJournals. Memories Youth. Practicesof Reading and Writing 
O objetivo deste estudo é analisar o Colunas, periódico do Instituto Porto Alegre (IPA) ${ }^{1}$, em sua materialidade, bem como examinar os discursos presentes no impresso, procurando buscar possíveis marcas deixadas pelos alunos que estudavam em um colégio com características estrangeiras.

A coleção do Colunas é composta por vinte e quatro exemplares, disponíveis para consulta em dois lugares: o Museu Metodista de Educação Bispo Isac Aço (MMEBI), localizado nas dependências do Colégio Americano e a Biblioteca do Centro Universitário IPA Metodista, em Porto Alegre. De posse destas edições, investigou-se a temporalidade do periódico entre 1937 e 1954. Tal escolha se deve ao fato da importância de Oscar Machado da

Silva, um professor referência para a história da instituição, pois esteve à frente da Reitoria ${ }^{2}$ do IPA durante vinte anos, entre 1934 e 1954. Foi o primeiro brasileiro a ocupar o cargo da direção do Colégio, pois antes dele todos os outros Reitores eram de nacionalidade norteamericana. De acordo com o Colunas, Oscar Machado, apesar de sua forte identificação com a cultura estadunidense, enfrentou, no período do Estado Novo, o desafio de nacionalizar ${ }^{3}$ o Colégio, promovendo a construção de uma nova identidade ao IPA.

1 Colégio localizado na cidade de Porto Alegre/RS.

2 As expressões, Reitoria e Reitor, eram utilizadas no IPA devido à influência estadunidense em sua organização pedagógica e administrativa.

3 Até a década de 1930, a Reitoria do Collegeesteve a cargo de americanos e, devido às mudanças políticas e educacionais que aconteceram no Brasil no final da década de 1920, este modelo de gestão foi questionado pelas autoridades que organizavam a educação no país. De acordo com Bastos (2005, p.17), “o nacionalismo já estava presente nas discussões, debates e realizações educacionais desde a década de 1910" e buscava realizar uma ampla reforma intelectual fazendo com que os indivíduos gradativamente se adaptassem às exigências da nova realidade que se apresentava. 
O estudo situa-se no campo da História da Educação, em suas interfaces com a Imprensa Escolar e história das instituições de ensino, seguindo os pressupostos teóricos da História Cultural. Esta é uma corrente historiográfica de caráter interdisciplinar que procura se distanciar da história de cunho tradicional ao valorizar os sujeitos como aqueles que fazem a História de seu tempo. Para Maria Teresa Santos Cunha (1999), o alargamento das possibilidades investigativas a partir desta vertente historiográfica, possibilita ao pesquisador realizar estudos que valorizem outros "sujeitos e objetos até então inexplorados" (p. 41). Com esta perspectiva mais abrangente, política e economia deixaram de ser consideradas como centrais, abrindo espaço para os temas da cultura. Galvão e Lopes (2010) atentam que essa legitimação das pesquisas no campo da História da Educação se deve à renovação do olhar lançado sobre os objetos de análise e novas fontes que são legitimadas pela História Cultural.

Para além da História da Educação num sentido latu sensu, é importante analisar, ainda que brevemente, alguns de seus entrelaçamentos com a imprensa escolar e a história das instituições educativas. A imprensa escolar constitui-se em um corpus documental que carrega múltiplas faces do passado educativo no que diz respeito às práticas e às concepções pedagógicas e sociais, principalmente quando posta em relação com a sociedade além dos limites dos muros escolares (Catani e Bastos, 1997). Produzidos e publicados por alunos, professores ou instituições e atravessados por diferentes intencionalidades, os jornais ou revistas escolares deixaram vestígios através dos quais podemos reconstruir alguns aspectos daquela complexa realidade.

Catani e Bastos (1997), ao citarem Pierre Ognier, dizem que a imprensa escolar apresenta uma espécie de testemunho vivo dos métodos e das concepções pedagógicas difundidas em uma época. Através da análise dos discursos veiculados nos jornais escolares,podemos nos aproximar dos códigos de uma época. Portanto, nesse diálogo 
com a História da Educação, entende-se que os periódicos escolares constituíam-se em uma das formas pelas quais professores, diretores e alunos validavam suas concepções sobre determinados assuntos e exercitavam práticas de escrita. Os textos e imagens dos periódicos escolares nos ajudam a compreender os modos de educar de uma determinada instituição de ensino.

\section{Do Porto Alegre College ao IPA}

De acordo com Mesquida (1993), o Metodismo iniciou no século XVIII na Inglaterra, como um movimento evangélico e educativo de renovação social, idealizado pelo pastor anglicano e professor da Universidade de Oxford John Wesley. Para esta pesquisa, importa dizer que o Metodismo chegou ao Estado do Rio Grande do Sul (RS) em 1875, trazido do Uruguai pelo missionário João da Costa Corrêa. Sua missão estava ligada à vertente Norte do metodismo americano e objetivava construir uma obra para realizar ações de evangelização e a criar escolas. Foi ele que, juntamente com a jovem Carmen Chacon, fundaram o Colégio Evangélico Misto $n^{\circ} 1$ instituição metodista que, mais tarde, viria a ser denominada como Colégio Americano, em funcionamento até a presente data no Bairro Rio Branco, em Porto Alegre. Estes primeiros missionários que se instalaram no RS, traziam os ideais de John Wesley quanto à educação feminina ${ }^{4}$ e para os pobres.

Apenas no começo do século XX,os missionários sulistas começaram a visitar o RS realizando estudos para a ampliação das obras que eram promovidas pelo país. Na década de 1910, diferentes

4 O Americano em Porto Alegre foi pioneiro em relação à escolarização das mulheres pela variedade de cursos oferecidos, alguns deles profissionalizantes. Essa preocupação com a formação profissional das alunas evidencia o significado desta instituição de ensino e sua importância para a história da educação das mulheres no Brasil. (ALMEIDA, 2013) 
ações foram realizadas entre ela, a que culminaria na fundação do Instituto Porto Alegre (IPA) na capital gaúcha.

Metodistas vindos da Faculdade de Teologia Southern MethodistUniversity(SMU) ${ }^{5}$ de Dallas/Texas (EUA), fundaram escolas em diferentes Estados e estas instituições se caracterizavam por oferecer um ensino que não era comparável ao ensino católico, até então,predominante no país. Os novos educandários se identificavam com as camadas mais favorecidas economicamente e estavam voltados, inicialmente, para os rapazes das famílias ligadas à Igreja Metodista. Com uma filosofia baseada nos ideais americanos de liberdade, democracia e progresso, entre outros, tinham o propósito de "atingir os filhos das elites dirigentes do país [...], pois através dos grupos dominantes é possível levar a influência da ética protestante aos poderes constituídos e então melhorar as condições da sociedade" (MENEGHETTI, 2008, p. 846).

Ao que tudo indica,tais escolas atendiam aos projetos da burguesia emergente entrelaçando o viés religioso e os valores do sistema capitalista ao preparar seus alunospara a liderança da sociedade brasileira.ConformeShroeder (1982), em 15 de fevereiro de 1923, o Instituto Porto Alegre foi inaugurado sob o nome Porto Alegre College, em um prédio alugado na Rua Marechal Floriano Peixoto, no centro da capital. Em 1924 houve a mudança da instituição para as dependências construídas especificamente para seu funcionamento no bairro Rio Branco, conhecido pelos alunos professores como Morro Milenar. Este novo apresentou a inspiração para nomear o anuário do colégio, devido às colunas existentes, até hoje, na entrada do prédio. A cidade,assim como todo o país, se modernizava e adquiria novos contornos e serviços, imersa em uma ordem urbano-industrial que irradiava padrões e valores burgueses. Cabe ressaltar que a influência estrangeira na economia gerou profundas implicações sobre os padrões de comportamento da

5 A SMU é uma universidade privada estadunidense afiliada à Igreja Metodista. 
sociedade e muitas cidades brasileiras incorporaram ao imaginário urbano as referências culturais norte-americanas.

A estrutura inicial do Collegehavia sido pensada para se tornar uma instituição de ensino superior ${ }^{6}$, inclusive mantinha a figura do Reitor ao invés do Diretor escolar. Os professores e administradores do College eram missionários americanos e suas esposas, quase sempre formados pela Faculdade de Teologia Southern MethodistUniversity(SMU) dos EUA.

\section{O aluno ipaense nas páginas do Colunas}

Durante os anos em que o IPA passou pelo processo de nacionalização de sua cultura escolar,o Reitor Oscar Machado da Silva parece ter estimulado a promoção de ações no sentido de que os alunos se sentissem participantes ativos da vida da instituição. Dentre as inovações pedagógicas realizadas em sua gestão, destacamos seu envolvimento como criador do livro anual denominado Colunas que tinha o propósito de "catalogar as atividades, o desenvolvimento e as memórias íntimas do IPA” (Colunas, 1937, p.40).

Primeiramente, chamamos atenção para o nome Colunasque faz referência direta à própria instituição. O prédio principal do IPA foi construído em estilo neoclássico e possui uma escadaria encimada por um pórtico com quatro colunas jônicas, sobre as quais, na faixa do frontão triangular, lê-se Instituto Porto Alegre. A visão desta fachada é bastante valorizada em todos os exemplares do anuário, nas capas e nas fotografias presentes nas seções, parecendo querer difundir a monumentalidade da instituição, eternizando-a.

Ao analisar de quem era a responsabilidade pela publicação

6 Em 1928 foi inaugurada a Faculdade de Teologia que, em 1938, foi transferida para Minas Gerais. Somente em 1970 o objetivo foi efetivamente atingido com a inauguração da Escola Superior de Educação Física. 
do Colunas, perceberamse algumas diferenças, ainda que sutis. A maioria dos impressos trazia na capa e folha de rosto uma inscrição dizendo que era "Uma Publicação do Instituto Porto Alegre" (1937, 1938, 1945, 1948, 1952 a 1954), claramente de cunho institucional. Entretanto,em três anos consecutivos,a inscrição foi modificada para uma "Publicação dos Alunos do Instituto Porto Alegre" (1949, 1950 e 1951). Cumpre acrescentar que nestas três edições não aparecem nomes de professores na nominata dos editores do periódico, diferentemente do observado nos outros exemplares.

Fora esta mudança, não é possível identificar diferenças significativas quanto às características gerais da editoração que indiquem maior ou menor grau de envolvimento dos alunos, pois há uma evidente padronização do anuário. Com base nisso, é de se pensar se, de fato, o Colunas refletia os discentes do IPA ou se constituía no principal modo de legitimação das práticas educacionais metodistas. Fica a indagação: quantos alunos será que efetivamente se envolviam com o anuário como autores ou leitores?

Ao observar todas as edições do Colunas constamos que, ao que parece, foram intencionalmente produzidos para serem guardados pelas famílias com vistas à perenidade. As palavras do Reitor na edição de 1951, reiteram a importância do anuário como uma memória dos tempos vividos no IPA:

O Olvido é um fenômeno psicológico tão natural quanto a Recordação. Por isso, nossa vida mental gira, em grande parte, entre dois pólos: a Memória e o Esquecimento. [...] Colunas não é uma obra feita para o Presente. Seu inestimável valor está em que, no Futuro, será uma fonte inexaurível de suaves recordações. (Colunas, 1951, p.02)

Para Oscar Machado, fundador do Colunas, o anuário talvez fosse um meio de perpetuar as memórias individuais e coletivas daquela comunidade. Para Halbwachs (1990), a memória é uma di- 
mensão das vivências física se afetivas e está presente na identidade de um grupo. Aqueles que lessem as páginas do impresso anos mais tarde, provavelmente não o leriam da mesma forma, cada um faria uma leitura própria das lembranças ali contidas, pois, de acordo com Stephanou e Bastos (2005), reconstruímos o passado a partir do que nos parece significativo, e ele "pode ser possuído diferentemente por muitos" (p. 420).

\section{O Colunas e seus protocolos de leitura}

Quanto à materialidade, constata-se que o Colunas não é um periódico com características efêmeras tal qual um jornal, isso se torna evidente no seu modo de editoração. A maioria das edições possui capa dura com encadernação tipo brochura, medindo $27,5 \mathrm{~cm}$ de altura por 19,5cm de largura e folhas em papel couche, denotando preocupação com a qualidade da apresentação do material. Conforme tabela a seguir, em cada exemplar a quantidade de páginas varia entre 150 e 250. Via de regra, são apresentados poucos textos e muitas fotografias que se repetiram por muitos anos, por exemplo, imagens da fachada e espaços do IPA, bem como fotografias de alguns professores e administradores. 
Tabela 1: Comparativo entre páginas e quantidade de fotografias

\begin{tabular}{ccc} 
Ano & Páginas & Fotografias \\
\hline 1937 & 82 & 386 \\
\hline 1938 & 134 & 392 \\
\hline 1938 & 174 & 528 \\
\hline 1940 & & Edição não localizada \\
\hline 1945 & 166 & 585 \\
\hline 1948 & 880 & 623 \\
\hline 1949 & 125 & 709 \\
\hline 1950 & 174 & 861 \\
\hline 1951 & 203 & 963 \\
\hline 1952 & 237 & 1.006 \\
\hline 1953 & 248 & 1.128 \\
\hline 1954 & 240 & 1.147 \\
\hline Total & $\mathbf{1 . 8 6 3}$ & $\mathbf{8 . 3 3 1}$ \\
\hline
\end{tabular}

A grande profusão de imagens, cerca de oito mil e trezentas, considerando os doze exemplares analisados, é um aspecto importante a ser considerado na trajetória de circulação do Colunas. Elas são tomadas aqui, no sentido de representações das vivências no Colégio e, longe de serem simples ilustrações, algumas podem ser identificadas como complementos dos textos escritos ou podem assumir significados maiores, como "protagonistas da mensagem escrita ao trazer à escola o mundo tal qual ele deve ser percebido" (BASTOS; LEMOS; BUSNELLO, 2006, p. 42).

De modo geral, entendemos que as fotografias faziam parte da construção e legitimação das ações de determinados grupos sociais, neste caso a consolidação do projeto ${ }^{7}$ Metodista de

\footnotetext{
7 Mesquida (1988) explica, que até a década de 1930, época da criação da maior parte dos colégios Metodistas no Brasil, o discurso que estava presente na instituição promovia o favorecimento da formação dos filhos da elite econômica ligada à Igreja Metodista. A intenção era de que os jovens educados em suas escolas estivessem aptos a conduzir a nação de modo consciente e afinado com os ideais americanos de democracia.
} 
formação do sujeito integral, apto a servir à sociedade moderna. para Monteiro

(2012), a publicação de imagens em jornais e revistas colaborava para "dar visibilidade, davam a ver certos grupos e práticas sociais, bem como construíam hierarquias e diferenças sociais" (p.31). Se pensarmos no Colunas, comparativamente ao Crisol, ou outros impressos escolares do mesmo período na cidade de Porto Alegre, a disparidade na quantidade de fotografias fica evidente, talvez devido aos investimentos estrangeiros que proporcionavam maiores recursos para sua publicação.

Fotografias escolares podem ser consideradas testemunhos de um modo de ser e de representar a escola, de acordo com Souza (2001, p. 79), elas "constituem um gênero de fotografias muito difundido a partir do início do século XX [...]. Entre os diversos tipos de conteúdos temáticos retratados, o mais popular é a foto de classe" que, notadamente é o estilo menos identificado em todo Colunas. Outras representações mais fluídas tentavam parecer espontâneas e retratavam momentos da vida escolar, ambientes do colégio com ou sem alunos, solenidades, atividades, viagens, festas, exposições escolares, aulas de educação física e os retratos de professores, reitores, inspetores e funcionários. Entende-se que esses registros visuais tiveram a intenção de legitimar discursos, símbolos, normas e valores presentes no periódico como "um instrumento de memória institucional e de recordação" (SOUZA, 2001, p. 78).

Apesar da pouca quantidade de textos no periódico, observam-se pequenas frases junto às fotografias que parecem ter propósitos maiores do que simplesmente explicar a imagem, ou seja, essas frases deixam revelar um pouco da filosofia do colégio e das concepções de educação daquela instituição metodista. Em 1949, temos um exemplo disso, em uma mesma página, há fotos da quadra de esportes e do prédio principal do IPA, ao lado delas acompanham as frases "Aqui se temperam os músculos..." e "...e aqui o caráter". 
Entendemos que, nesse caso, fotografias e escritos se unem exercendo um poder de persuadir o leitor para aderir ao discurso do significado de ser aluno daquele lugar. Chartier (1998) nos ajuda a compreender que as imagens não devem ser encaradas como simples ilustrações contidas nos impressos, elas possuem uma motivação mesmo que inconsciente para serem utilizadas em determinados lugares e com determinados textos, o que parece ficar muito claro no caso deste periódico. Cumpre lembrar que imagens e textos constituem-se em protocolos de leitura, ou seja, elementos disseminados pelo autor no texto para indicar aquele que lê o tipo de apropriação que deve fazer dos significados contidos em suas páginas (Chartier, 1996).

Desde o primeiro volume do Colunas, observa-se constantemente a imagem da fachada do prédio do IPA adornando as capas. Poucas variações são vistas nas cores, nas letras, nas impressões em baixo relevo e nas fotografias das colunas que são retratadas pelo ângulo da direita ou esquerda. De 1952a 1954, são os únicos anos em que há na capa o acréscimo da frase "Publicação do Instituto Porto Alegre", logo abaixo do nome do anuário, demonstrando ser um material oficial da instituição.

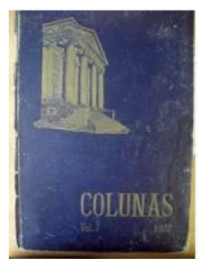

1937

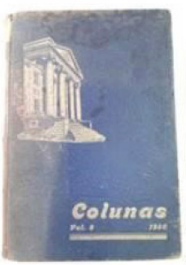

1950

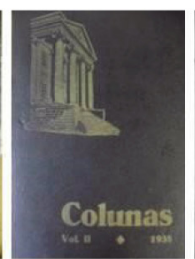

1938

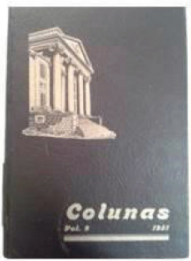

1951

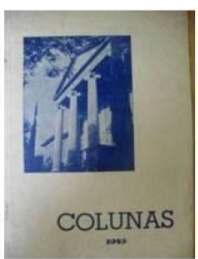

1945

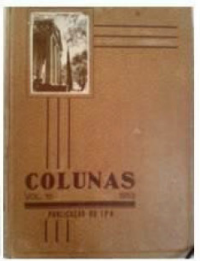

1952

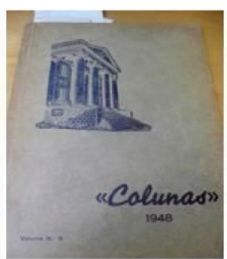

1948

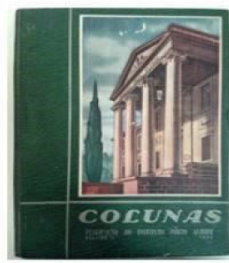

1953

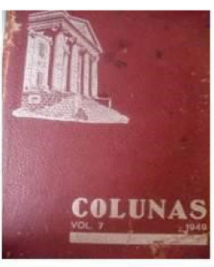

1949

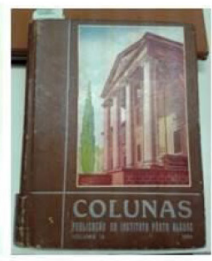

1954

Fonte: $M M E B I$ 
O modelo editorial deste periódico, assim como diversas outras características do IPA apresentadas ao longo deste texto, parece fortemente inspirado nos padrões dos yearbooks ${ }^{8}$ norte-americanos, principalmente os publicados pelas instituições nas quais o Reitor Oscar Machado estudo una década de 1920. Formado em Pedagogia pelo Birmingham Southern

College do Alabama e em Filosofia pela Southern MethodistUniversity (SMU) de Dallas (GOMES, 2003), Oscar Machado parece ter incorporado à vida do IPA muitos elementos com os quais teve contato durante sua estada nos EUA. As semelhanças entre o Colunas, o La Revue do Birmingham e o Rotunda da SMU são incontestáveis, por este motivo merecem destaque. Ambos yearbooks são editados até a presente data e encontram-se disponíveis para consulta online nas páginas das Universidades ${ }^{9}$. Com isso, vemos que as capas, as folhasde rosto, oseditoriais, asseções, otratamentodas imagens e dos textos vão além de uma mimetização, pode-se dizer que há uma imitação com conotação de cópia das publicações americanas, conforme imagem a seguir.

8 Livros anuais publicados pelas escolas e universidades norte americanas com fotografias dos alunos, professores e outros aspectos da vida escolar, incluindo espaços para assinaturas e mensagens.

9 Rotunda, SMU - http://memories.smu.edu/La Revue, Birmingham- https://archive. org/details/birminghamsouthern 

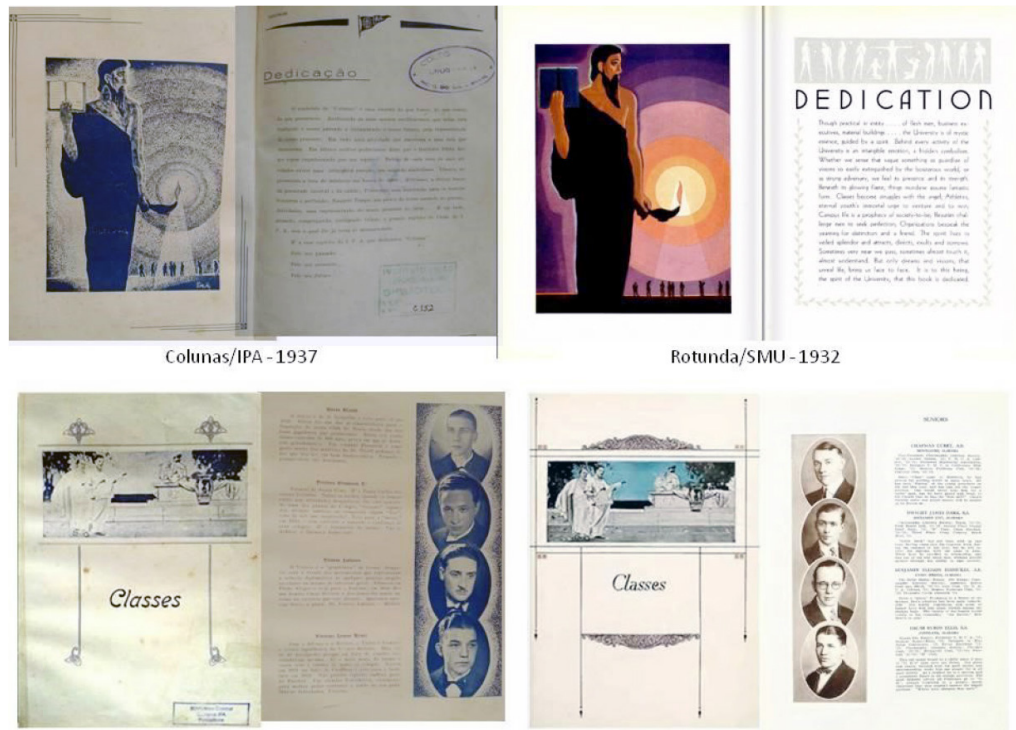

La Revue - Birmingham Southern College - 1924

Fonte: La Revue e Rotunda - online e Colunas - MMEBI

Alguns títulos do Colunas são como traduções das seções dos periódicos americanos. Em rápida análise,vemos que os textos e o modo como as fotografias são apresentadas também possuem muitas aproximações aos yearbooks, por exemplo, as seções: Dedicação/Dedication - normalmente dedica o anuário a um antigo reitor ou professor;

Editores/Editors - apresentam os alunos e professores que trabalharam como editores no ano; Alma Mater/Alma Mater - textos e fotografias que mostram a grandiosidade das instituições;Classes/ Classes - fotografias e breves biografias dos alunos. Entre outras características, os elementos gráficos utilizados nas edições analisadas do Colunas, sugerem que o professor Oscar Machado trouxe um modelo pronto para ser implantado no IPA com poucas adaptações. 
Assim, texto, suporte e escrita são três elementos que não existem separadamente e que estão imbricados um no outro. No Colunas, parece haver certa intenção de aproximar a realidade dos jovens gaúchos aos padrões americanos que intencional e gradativamente estavam sendo implantados na sua formação. Longe de pensar que essa seja uma questão secundária, Chartier (2002) explica que os textos não são abstratos ou neutros e não existem fora de sua materialidade.

Anualmente, a organização do periódico ficava a cargo de uma equipe editorial, normalmente composta por alunos e professores. A responsabilidade desse grupo era registrar por meio de fotografias e pequenos textos, os acontecimentos que expressassem os múltiplos elementos da vida escolar ao longo do ano. Provavelmente, para garantir a melhor qualidade das imagens que seriam divulgadas, todas as fotografias eram feitas por fotógrafos de estúdios contratados pelo colégio. Ao examinar as fotografias, identificamos a presença do StúdioCarraro e do senhor Armando Czamanski, que por muitos anos, conviveram no dia a dia do IPA, sendo responsáveis pela produção fotográfica daquilo que foi considerado relevante para ser publicizado.

De acordo com Monteiro (2012), foi a partir da Segunda Guerra Mundial que os fotógrafos passaram a ter seus nomes mencionados como autores das imagens publicadas em jornais e revistas ilustradas, mas no Colunas, observa-se que desde a primeira edição, datada de 1937, todas as fotos aparecem assinadas, talvez fosse uma maneira de divulgar os serviços dos profissionais ao público leitor. Quanto à fotografia, o mesmo autor destaca que ela "é uma convenção do olhar e uma linguagem de representação e expressão de um olhar sobre o mundo" (Ibdem, p.14), deste modo, está sujeita as mais diversas interpretações e leituras.

Pode-se dizer que a leitura do periódico, feita por alunos, familiares, professores e exalunos suscitava naqueles que conhecessem 
a Escola Magestosa ${ }^{10}$, um olhar saudosista daquele Segundo Lar que transmitia saberes que oportunizavam a "transformação de rapazes em homens" (Colunas, 1945, p. 06). O anuário, rico em imagens, eternizaria um "mundo de recordações suaves e amigas [ao] rever suas fotografias! Toda vida do IPA [...] perpassava [a] imaginação em lances sucessivos e emocionantes" (Colunas, 1951, p. 23). Para muitos, talvez o Colunas fosse parte do álbum de família, um "objeto impregnado de afetividade e recordação” (SOUZA, 2001, p. 79).

\section{Exame dos Discursos: as marcas dos alunos no Colunas}

A imprensa escolar permite apreender um pouco da cultura do IPA e o periódico

Colunasnos instiga a perceber algumas práticas educativas daqueles tempos. Segundo Fischer (2004), inspirada em Foucault, os periódicos influenciam o processo de subjetivação dos leitores. Os discursos que se apresentam nos textos consultados ajudam a constituir o próprio objeto de que falavam aqueles estudantes. Estes jovens testemunharam significativas transformações no cenário educacional brasileiro, entre 1930 e 1950, que culminaram em mudanças internas no IPA.

Identificam-se no Colunas, dois tipos de discursos, um de exaltação aoIPA e ao próprioanuário Colunas e outro que transgride a regra de glorificar a instituição, talvez como forma de não aceitação e de contestação velada às práticas difundidas pelo Reitor Oscar Machado. Ao analisar o periódico, é importante entender a participação dos alunos como escreventes, tendo clareza que quando se lê um texto, se dialoga com uma rede de autores, para além dos

10 Ao longo das edições do Colunas, o IPA é denominado como Escola Majestosa, Gigante de Granito ou Segundo Lar localizado no Morro Milenar. As expressões procuravam demonstrar a grandiosidade do Colégio. 
alunos. Ou seja, a autoria do anuário está em questão, juntamente com a interferência empregada pelo Reitor, o editor, o tipógrafo, o fotógrafo e os professores. Esses atravessamentos promovem transformações discursivas nos textos e nas imagens trazidas como expressões espontâneas nas páginas do Colunas.

Percebem-se, ao longo dos anos, muitas intervenções dos professores e administradores do IPA na escrita dos textos publicados, bem como nas fotografias escolhidas para representá-las. O Colunas era, possivelmente, o principal meio de "informar e divulgar as iniciativas do colégio, um instrumento de propaganda [...].Parece que se publicava aquilo que era de interesse da instituição e que, portanto,colaborava para forjar uma imagem positiva" (ALMEIDA, 2013, p.277) sobre as melhores praticas do colégio. Ou quem sabe, o Colunas não seria um meio de legitimar as ações do Reitor Oscar Machado e eternizar seu nome na história da Instituição?

Oscar Machado foi um dos autores que mais publicou textos no anuário no período analisado. Seus escritos exaltavam a Escola Magestosa, além de constantemente salientar a importância da publicação do Colunas como um meio para manter o "Espírito Ipaense ${ }^{11}$ " vivo para as gerações futuras. Falava aos leitores sobre o tempo glorioso em que viviam e do quão abençoados seriam aqueles que, no futuro, pudessem recordar do IPA como um "manancial de recordações. Que momentos felizes! Teremos muito que recordar [...] e quando estivermos velhos com nossa missão cumprida aqui na terra [...] Colunas nos fará viver novamente" (Colunas, 1950, p. 19). Talvez hoje, seja possível dizer que, de certa forma, seu objetivo em perpetuar a materialidade deste anuário tenha sido atingido.

${ }_{11}$ NosCollegesamericanos, há uma espécie de aura, denominada a Alma Mater. Uma atmosfera espiritual que produz nos alunos uma marca profunda que os acompanha ao longo da vida (OLIVEN, 2005). No IPA, esta experiência foi expressa pelo "Espírito Ipaense", um sentimento de pertencimento à escola, "que a todos invade e que continua pela vida com cada um, orientando, esclarecendo e sublimando atos e palavras" (Colunas, 1938, p. 14). 
Contudo, com a modernização e a dissolução da escola básica do IPA, em 2003, tais memórias são apenas vestígios daquele tempo, presentes nas prateleiras da Biblioteca do Centro Universitário IPA e no Museu do Colégio Americano.

Para além dos escritos do Reitor Machado, vemos que os professores também estavam encarregados de transmitir aos jovens a consciência de que faziam parte de uma instituição sui generis que seria a responsável não apenas por seus destinos, mas pela constituição de suas personalidades. Em um texto intitulado "Recordar é Viver", publicado em 1951, o professor João Henrique Fassina, docente de Língua Portuguesa e Francesa escreve um texto como se falasse aos antigos alunos, procurando fazer um ligeiro apanhado dos passos que os conduziram até a Escola Magestosae que, a partir dela se "aprimorou a personalidade, amoldou o caráter" e os levou pelo caminho do sucesso e da felicidade para um "futuro promissor" (Colunas, 1951, p. 07). A ideia deste e de outros textos, parece indicar um desejo da instituição de que o Colunas fosse lido durante muitos anos e que os alunos fossem capazes de recordar os melhores momentos de suas vidas e conferir ao IPA o devido reconhecimento pelo sucesso alcançado.

Pelo fato dos textos não serem neutros e possuírem uma intencionalidade, percebe-se que os próprios alunos se apropriaram dos discursos de exaltação ao IPA. Em 1954, o aluno Luiz AntonioCecchini da $4^{\mathrm{a}}$ série ginasial, aborda as características que ajudam a construir e fomentar recordações sobre a instituição, já que "quando sairmos do IPA apresentaremos traços marcantes de nossa personalidade. Levaremos um manancial de recordações de parte da nossa vida passada no Morro Milenar [...] devido a grandiosidade do Espírito Ipaense, latente em todos aqueles que passaram por nossa escola" (Colunas, 1954, p.65). Assim, o IPA e o Colunas funcionam como lugares de memória que eternizam lembranças e fazem referências a pessoas, cenários e acontecimentos através das imagens e narrativas 
que apresenta. De acordo com Pierre Nora (1993), não somos feitos de esquecimentos, mas de lembranças que precisam ser estimuladas, pois as memórias não são espontâneas, por isso se faz necessário criar meios que ajudem na operação de recordar.

Apesar do Colunas constituir-se em um instrumento que legitimava os discursos que valorizavam a instituição, sutilmente ele se transformou em um espaço de transgressão que divulgava certas críticas a algumas práticas de alunos e professores. Havia uma seção chamada Formandos e nela os editores escreviam pequenas biografias sobre os alunos que concluíam a escolarização. Em meio a indicação da cidade de origem, idade, data que chegou ao Morro Milenare expectativas do formando quanto ao seu futuro, havia uma ou outra frase irônica sobre as qualidades e características dos colegas:

“[...] é um dos bons alunos da classe, mas o mal dele é o fraco pelas morenas";

"Segundo as más línguas, o Chibo [...] ainda não se acordou. Seu sonho é Medicina [...] se acordar em tempo." (Colunas, 1948, p.21).

Um discurso que foge daqueles observados até 1951, é a divulgação de imagens que parecem criticar os docentes. Tratam-se de alegorias usando recortes de fotografias dos rostos dos professores que foram colados em rústicas montagens fotográficas, normalmente em situações de sala de aula. Este é o caso do professor de Matemática, Cayoby de Oliveira, retratado segurando um ralador, pois "é o inventor do ralômetro, cuja finalidade precípua é descobrir os sapientes" (Colunas, 1951, p.85). 


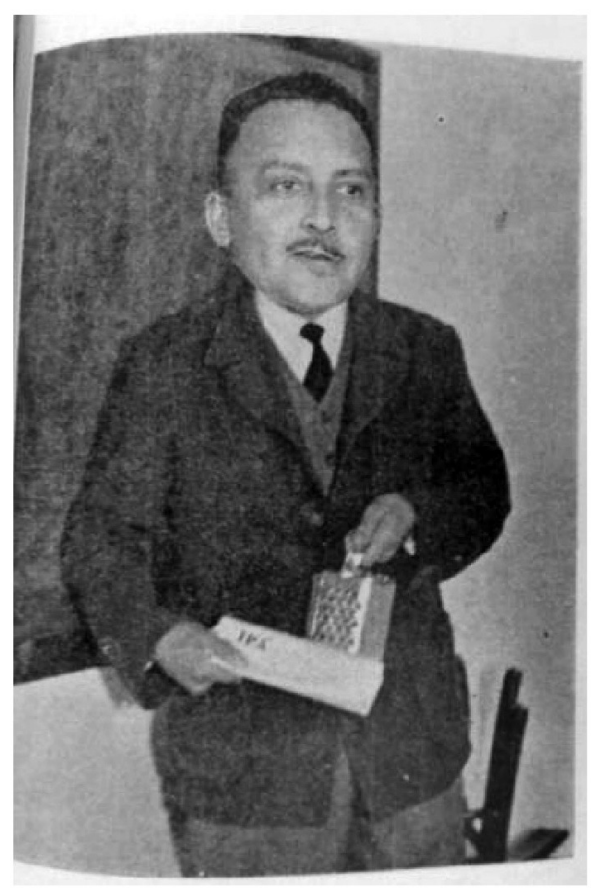

Fonte: Colunas, 1951, p.85

Assim como as biografias dos formandos que ironizavam as atitudes de alguns colegas, estas montagens talvez fossem o modo dos alunos avaliarem os docentes em uma época que suas opiniões talvez pouco fossem consideradas. Embora esta imagem possa suscitar diferentes interpretações, fica evidente pelo texto que a acompanha, que este professor era aquele que os alunos consideravam durão, seja porque talvez reprovasse ou cobrasse excelentes resultados dos alunos sapientes.

Deste modo, a visão do docente com uma cabeça desproporcional a um corpo que não lhe pertence, pode ser encarada como uma representação da realidade e dos sentimentos vividos por aqueles 
jovens. Segundo Pesavento (2003) "representar é, fundamentalmente, estar no lugar de [...]" (p. 40), não como uma cópia fiel do real que representa, mas como uma construção feita a partir dele e que pelo simbolismo que carregam, "dizem mais do que aquilo que mostram ou enunciam, carregam sentidos ocultos" (p.40).

Apesar da presença dos alunos ser menos constante no Colunas do que as do Reitor e professores, quando as identificamos, salta aos olhos a riqueza das possibilidades de análise daquilo que mostram. De 1938 a 1951, publicou-se uma série de desenhos nas divisórias das seções do anuário que foram identificados como charges.

Conforme Alves, Pereira e Cabral (2013), a charge pode ser encarada como um texto que possui elementos verbais e não verbais que possibilitam a leitura de sua manifestação comunicativa. Seu papel "é o de contradizer de forma sutil, inteligente e bem humorada o que é posto como inquestionável" (p.422), além de fazer uma crítica sobre temas contemporâneos ou pessoas conhecidas no meio onde a charge circula. De acordo com as autoras, o público se sente atraído por este tipo de representação, pois a leitura da imagem normalmente é de fácil compreensão e transmite múltiplas informações de forma condensada.

As charges do Colunas normalmente faziam referência ao ambiente escolar, porém outros lugares, ações e personagens alheios à escola são percebidos. Para Pilla e Quadros (2009), ao analisarmos o sentido do discurso presente nas charges, é necessário atentar para as estratégias, "muitas vezes silenciosas e sutis, que insinuam leituras e escrituras no fio discursivo. Em síntese, observar os jogos cênicos, as entrelinhas, o explícito e o implícito, o dito e o não dito" (p.2). As mais emblemáticas são aquelas que retratam professores e alunos, muitas vezes, estereotipados. Na seção Professores, os docentes são representados como velhos, com semblante austero, rodeados por livros e portando óculos ou bengala, objetos marcadores de uma idade avançada, quiçá de senilidade. Apenas na edição de 1949, a figurado professor, embora também seja de um velho, apresenta fei- 
ções amenas e parece dançar enquanto segue seu caminho carregando alguns livros. Destacamos que, em 1938 e 1950, uma mesma imagem foi publicada, variando apenas o tamanho da impressão, nela um professor sisudo e careca em pé atrás de uma mesa, segurando um livro com a mão esquerda enquanto a mão direita, em riste, parece passar um sermão. Embaixo da mesa encontra-se algo que parece uma dinamite. A imagem não oferece pistas para identificar quem era o professor alvo do desejo de que explodisse, mas talvez possa fazer recordar as críticas apresentadas anteriormente.

Figura: Representação dos professores nas charges das seções do Colunas.

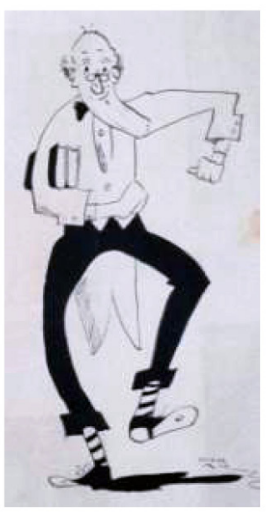

Colunas, 1949

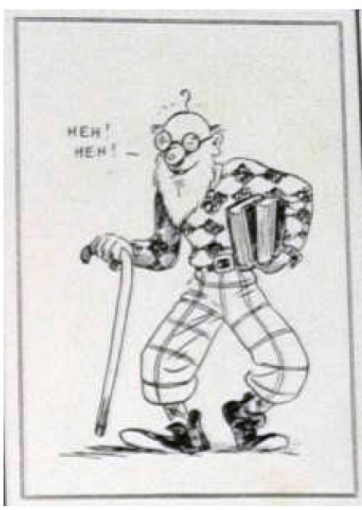

Colunas, 1939

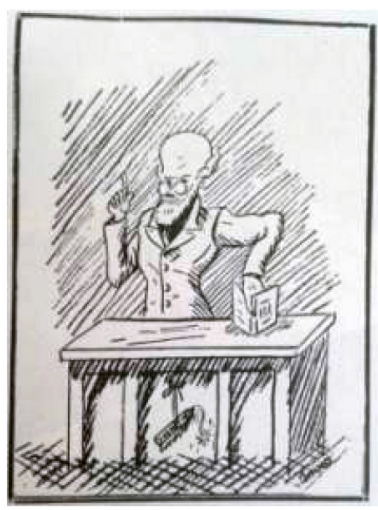

Colunas, $1938 / 1950$

Outra representação carregada de simbolismo é a das charges em os próprios alunos se retratam. A seção Classes é composta por fotografias, individuais e de classe, e pela nominata dos alunos que haviam estudado no IPA no ano da publicação. Os desenhos a seguir mostram rapazes em duas situações distintas, dentro e fora da escola. Há uma clara diferença entre estas imagens, pois quando estão no ambiente escolar se identificam como pessoas cansadas, desanimadas e que parecem desejar fugir de opressoras pilhas de livros prestes a cair sobre eles. 
Figura: Representação dos alunos dentro da Escola

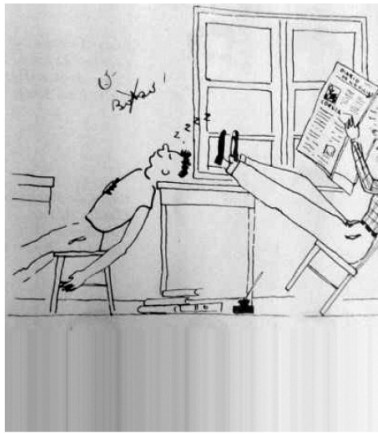

Colunas, 1938

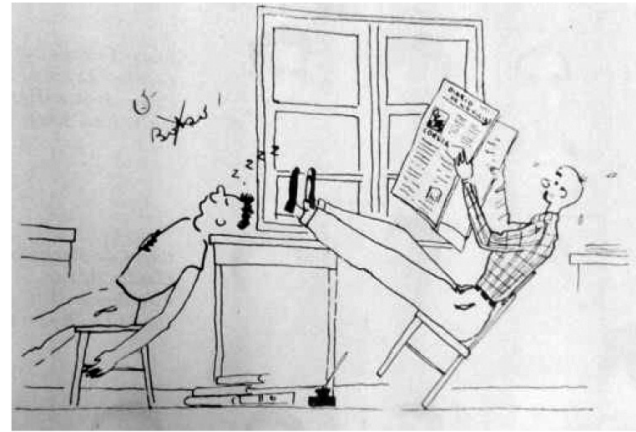

Colunas, 1949

Fora do ambiente escolar, liberdade, alegria e prazeres próprios da idade dão o tom daquilo que querem expressar, como, namoro, descanso, brincadeiras coisas que não possuem espaço dentro do colégio.

Figura: Colunas, Representação dos alunos 1949 fora da Escola

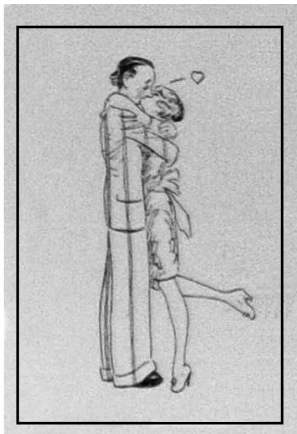

Colunas, 1939

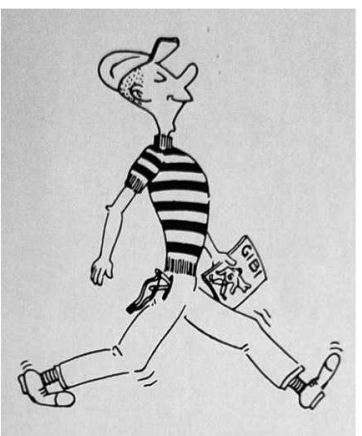

Colunas, 1949

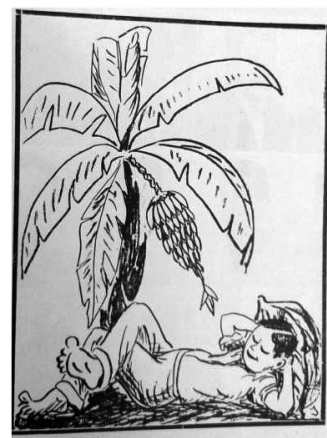

Colunas, 1938 
O caráter institucional do Colunas não impediu que as vozes dos alunos ecoassem nas páginas do anuário. Em meio à profusão de fotografias e notícias do colégio, eles se fazem notar, especialmente nos textos biográficos dos colegas, nas montagens fotográficas e nas charges. Essas são marcas dos discentes, talvez pouco perceptíveis em um primeiro olhar, mas que se revelam na observação atenta desta fonte importante para a História da Educação.

\section{Considerações finais}

O propósito deste estudo foi analisar a materialidade do periódico Colunas, bem como alguns discursos presentes no anuário. Consideramos este impresso um dispositivo privilegiado que possibilita uma melhor compreensão e percepção do contexto formativo dos sujeitos pertencentes acultura escolar do IPA Metodista.

A partir da classificação do acervo consultado, como uma espécie de inventário, selecionou-se aquilo que, de alguma forma, interpelava nossa subjetividade de pesquisadoras, a fim de indagá-los e problematizá-los.

O anuário Colunas, fortemente atrelado ao formato estético e discursivo de dois yearbooks americanos acabou possibilitando a divulgação de algumas marcas de transgressão que, através de charges, satirizavam acontecimentos e personagens do universo escolar. Quem sabe os alunos, ávidos por colocar em prática o tão difundido protagonismo estudantil, tenham sutilmente, criticado a gestão escolaratravés de seus traços. Mas resta a dúvida, será que os criticados entenderam?

É importante enfatizar que este estudo é uma contribuição para a História da Educação, principalmente pensando nas escritas juvenis que por tanto tempo foram esquecidas pela historiografia oficial da educação, portanto, busca-se valorizar as produções desses sujeitos. 
Por fim, cabe destacar o valor do museu, no caso o Museu do Colégio Americano,enquanto lugar de memória preocupado em preservar e transmitir lembranças de um outro tempo. Sem ele, talvez não fosse possível acessar tantas edições que foram eternizadas pelo colégio ou famílias que para lá levaram seus anuários no afã de perpetuar aquelas memórias que foram colocadas em um suporte diferenciado, justamente para ser preservado.

\section{Referências}

ALMEIDA, Dóris Bittencourt. O Crisol: Periódico das Alunas do Colégio Americano (Porto Alegre/Rs, 1945-1964). In: Revista da Educação - RHE, v. 17, p. 267-290, 2013. ALVES, Telma Lucia Bezerra, PEREIRA, Suellen Silva, CABRAL, Laíse do Nascimento. A utilização de charges e tiras humorísticas como recurso didático-pedagógico mobilizador no processo de ensino-aprendizagem da GeografiaEducação. Revista do Centro de Educação 2013, Disponível em:http://www. redalyc.org/articulo.oa?id=117127493015 > ISSN 01019031. Acesso em: 02 jul. 2014 BASTOS, M.H.C.; LEMOS, E.A.; BUSNELLO, F. B. Pedagogia da Ilustração: uma face do impresso. In: BENCOSTTA, Marcus Levy A. (Org.) Pesquisa Sobre Cultura Escolar: perspectivas históricas. São Paulo: Cortez, 2006.

BASTOS, Maria Helena Câmara. A Revista do Ensino do Rio Grande Do Sul (1939 - 1942): O novo e o nacional em revista. Pelotas: Seiva, 2005

CATANI, Denice Bárbara; BASTOS, Maria Helena Câmara. Apresentação. In: (Orgs.). Educação em Revista: A imprensa periódica e a história da educação. São Paulo: Escrituras, 1997. p. 5-10.

CHARTIER, Roger. As Utilizações do Objecto Impresso. Miraflores: Difel, 1998. . Práticas da leitura.São Paulo : Estação Liberdade, 1996. 268p.

. O Mundo como Representação. In: . À Beira da Falésia: a história entre incertezas e inquietude. Trad. Patrícia Chittoni Ramos. Porto Alegre: Ed.

Universidade/UFRGS, 2002, p. 61-80.

CUNHA, Maria Teresa Santos. Nas Margens do Instituído: memória/educação. In. História da Educação. ASPHE/FaE/UFPel, Pelotas (5): 23-38, abril de 1999. FISCHER, Beatriz Daudt. A Professora Primária nos Impressos Pedagógicos. In. 
STEPHANOU, Maria e BASTOS, Maria Helena Câmara (orgs.). Histórias e Memórias da Educação no Brasil, v. 3. Petrópolis: Vozes, 2004, p.324-335.

GALVÃO, Ana Maria de Oliveira; LOPES, Elaine Marta Teixeira. Território Plural: a pesquisa em história da educação. São Paulo: Ática, 2010.

GOMES, William B. Pesquisa e Prática em Psicologia no Brasil. 2003. Disponível em: http://www.ufrgs.br/museupsi/biooscarmachado.htm. Acesso em: 13 mar. 2014.

HALBWACHS, Maurice. A Memória Coletiva. São Paulo: Vértice, 1990

MENEGHETTI, Rosa GitanaKrob. A Proposta Educacional Metodista no Brasil. HISTEDBR - Grupo de Estudos e Pesquisas História, Sociedade e Educação no Brasil Anais do IV Seminário Nacional. 2008 Disponível em: http://www.histedbr. fae.unicamp.br/acer_histedbr/seminario/seminario4/trabalhos/trab079.rtf. Acesso em: 31 mai. 2014

MESQUIDA, Peri. Metodismo e Educação no Brasil: formar elites e civilizar a nação. In: Revista do COGEIME. Encontro Nacional, Piracicaba, 1988.

. Metodismo e educação no Brasil: formar elites e civilizar a nação. In: Revista do COGEIME. do COGEIME Piracicaba, 2 (2): 1993.

. Hegemonia Norte-Americana e Educação Protestante No Brasil. Juiz de Fora/São Bernardo: Ed. UFJF/Editeo, 1994.

MONTEIRO, Charles (org.). Fotografia, História e Cultura Visual: pesquisas recentes. Porto Alegre: EDIPUCRS, 2012.

NORA, Pierre. Entre Memória e História: a problemática dos lugares. Projeto História. São Paulo: PUC-SP. N 10, 1993.

OLIVEN, Arabela Campos. A Marca de Origem: comparando Colleges norte-americanos e Faculdades brasileiras. In: Cadernos de Pesquisa, v. 35, n. 125, p. 111-135, maio/ago. 2005. Disponível em: http:/www.scielo.br/pdf/cp/v35n125/ a0735125.pdf. Acesso em: 19 jun. 2014.PESAVENTO, Sandra Jatahy. História e História Cultural. Belo Horizonte: Autêntica, 2003.

PILLA, A.; QUADROS, C. B..Charges: uma leitura orientada pela Análise do Discurso de linha francesa. Disponível em: http://www.intercom.org.br/papers/ nacionais/2009/resumos/R4-2082-1.pdf. Acesso em: 05 jun. 2014.

SCHROEDER, Edni Oscar. Analise da Proposta Educacional das Escolas Metodistas. Dissertação de mestrado em Educação (FGV) 1982 Orientador: Elter Dias Maciel. Disponível em: http://bibliotecadigital.fgv.br/dspace/bitstream/handle/10438/9115/000047289.pdf?sequence=1 . Acesso em: 12 fev. 2014 
SOUZA, Rosa Fátima de. Fotografias Escolares: a leitura de imagens na história da escola primária. In: Educar em Revista, Curitiba, n. 18, p. 75-101, 2001, Ed. UFPR. STEPHANOU, Maria e BASTOS, Maria Helena Câmara, Beatriz Daudt. Introdução. In. (orgs.). Histórias e Memórias da Educação No Brasil, v. 3. Petrópolis: Vozes, 2005. 